\title{
Anxiety, imagery, and sensory interference
}

\author{
EILEEN D. EDMUNSON and DOUGLAS L. NELSON \\ University of South Florida, Tampa, Florida 39620
}

\begin{abstract}
Recently it has been suggested that high-anxious subjects do not process words as extensively as low-anxious subjects. Within the levels-of-processing models of memory, this suggests that high-anxious subjects focus on the sensory aspects of verbal material (graphic and phonetic), while low-anxious subjects organize their learning around semantic features. High and low trait anxious subjects were given a paired-associate task involving words that were high or low in sensory similarity, and they were given either an effective learning strategy, interaction imagery, or a poor one, repetition. State anxiety measures also were obtained. The results suggest that: (1) The differences in performance between high and low trait anxious subjects are nearly eliminated by an effective strategy such as interaction imagery; (2) high state anxious subjects are more impaired by high similarity than are low state anxious subjects.
\end{abstract}

The detrimental effects of anxiety on complex cognitive tasks are well documented (Spielberger, 1966), but little is known about the manner in which anxiety impairs performance. A recent attempt to investigate the effects of anxiety on cognitive processes relates this state to levels-of-processing models of human memory. These models postulate that words are represented in memory as complexes of independent features, including phonetic, graphic, associative, semantic, and imaginal (e.g., Bower, 1967; Wickens, 1970). This notion has been extended to include the idea that these features can be placed in a continuum ranging from sensory features (graphic and phonetic) to meaning features (associative, semantic, or imaginal). Presumably, a different level of coding is involved in the processing of meaning representations than in the processing of sensory representations (e.g. Craik \& Lockhart, 1972; Nelson, Wheeler, Borden, \& Brooks, 1974; Posner \& Warren, 1972). Recent evidence suggests that anxiety may influence the level of processing which is achieved (Schwartz, 1975; Mueller, Note 1). High-anxious subjects do not appear to process words as extensively as low-anxious subjects. They may, for example, attend to task-irrelevant cues or they may perseverate on some idiosyncratically salient attribute, thereby preventing the processing of other attributes. This limited processing could lead to a reduction in the encoding of meaning attributes with a corresponding increased focus on sensory attributes. For example, in a paired-associates task, high-arousal subjects make more errors when the response words are phonetically similar than when they are semantically similar. Subjects low in arousal exhibit the opposite pattern of performance (Schwartz, 1975). Similar trends are reported by Mueller (Note 1).

This research was supported by Grant MH 16360 to the second author from the National Institute of Mental Health. This research served to partially fulfill the requirements for the MA degree for the first author. Requests for reprints should be sent to Douglas L. Nelson, Department of Psychology, University of South Florida, Tampa, Florida 33620.
The present experiment was designed to investigate the relationship between anxiety and cognitive processing. High and low trait anxious subjects were selected on the basis of the STAI (State Trait Anxiety Inventory, A-Trait Scale). In addition, two state anxiety measurements were taken during the experiment in an attempt to measure the actual amount of anxiety present (STAI, A-State Scale). Thus, anxiety is measured as a trait and a state characteristic. According to Spielberger's (1966) analysis, trait anxiety is a personality disposition which causes the individual to experience this state anxious condition with greater frequency than others. State anxiety is the unpleasant feeling of tension and apprehension that occurs when an individual interprets specific situations as personally threatening.

Each subject learned a paired-associate list composed of pairs of words that were high in rated imagery value. The stimulus words of these lists were similar or dissimilar in graphic-phonetic attributes, and the instructions provided the subjects either with an effective learning strategy, interaction imagery, or with a poor one, repetition. If differential attention to the sensory attributes of words is one consequence of anxiety, the performance of more highly anxious subjects should be more impaired by graphic-phonetic stimulus similarity than that of less anxious subjects. In addition, if highly anxious subjects are less likely to spontaneously use semantic or imaginal attributes in organizing their learning, then an instructional set that orients subjects toward imaginal processing may be of more help to high- than to low-anxious subjects. With an effective learning strategy, the deleterious effects of anxiety may no longer be apparent.

\section{METHOD}

\section{Experimental Design}

The experiment involved three between-subject variables, similarity, instructional set, and trait anxiety. Stimulus words were either high or low in formal similarity; and half of the subjects were given imagery instructions and half were given 
repetition instructions. For the trait anxiety variable, high and low trait anxious subjects were selected on the basis of STAI A-Trait scores.

\section{Subjects}

One hundred and twenty-eight students from the Introduction to Psychology course at the University of South Florida served as subjects, with 16 subjects assigned to each of the eight experimental conditions. Participation was voluntary, although extra credit points were given. Each subject was given a State-Trait Anxiety Inventory, A-Trait Scale (Spielberger, Gorsuch, \& Lushene, 1970) as part of a battery of tests routinely administered to the introductory psychology class. Two extreme groups were selected, those whose STAI A-Trait scores fell within the upper $25 \%$ of the class (high trait anxious group) and those with STAI A-Trait scores in the lower $25 \%$ of the class (low trait anxious group).

\section{Verbal Material}

There were two comparable lists of high-similarity concrete word pairs (cf. Nelson, Wheeler, \& Brooks, 1976). In the high-similarity conditions all the word stimuli within a list shared the first two letters; and, in addition, each list of 20 words was divided into five sets of four words which also shared terminal letters. In the low-similarity lists, stimulus words were chosen to be as different as possible from each other in graphic and phonetic similarity. All responses were taken from the Paivio, Yuille, and Madigan (1968) imagery and concreteness norms. Both high- and low-similarity lists were composed of highimagery word pairs and were equated with respect to imagery value using procedures employed by Paivio et al.

\section{Procedure}

Practice was by the study-test method, with all subjects continuing the task until they reached a criterion of two errorless trials. On the study trials, each word pair was presented for $3 \mathrm{sec}$. The test trials were self-paced and each subject was required to pronounce the stimulus before anticipating the response. Guessing was encouraged but not required. A Kodak Carousel projector was used to present slides of all items, with an auxiliary timer used to control all timing operations. All the slides were arranged in an unsystematically varied order, but in order to minimize recency effects, at least four slides appeared between any pair and the corresponding stimulus test slide.

All instructions were taped and were presented over an intercom system in order to keep the interaction between subject and experimenter as consistent as possible across all conditions. The initial instructions described the nature of the experiment, the study-test procedure, and, in addition, specified a "most efficient" strategy for learning the word pairs. The subjects in the imagery condition were told to construct a mental picture or image containing both of the words in the pair, so that the images formed for each of the words interacted together. Several examples illustrating this concept were provided and each subject was asked to describe his image for several word pairs. The subjects given repetition instructions were told to repeat the words aloud, over and over again. Following these instructions all groups completed the state scale of the STAI. This first measure, State-1, was intended to assess each subject's state anxiety level as he entered the experimental task. Following the completion of the STAI, all subjects were given a short practice task to insure their understanding of the instructions. Further instructions were given to subjects whose behavior did not initially conform to their condition. All subjects were then presented the experimental task. As soon as the criterion level of learning was reached, all subjects again completed the STAI A-State Scale. This second administration, State-2, was used in an attempt to measure anxiety experienced over the task. Admittedly, this measure is imprecise, for state anxiety levels may have fluctuated considerably from the initial study trials to the later study trials. The use of a global retrospective measure was based on a desire to preserve the experimental task as intact as possible.

\section{RESULTS}

Table 1 presents the mean total errors (and standard deviations) per subject as a function of the principal conditions. Comparison of these values indicated that high similarity produced interference in all conditions, that an imagery strategy improved performance relative to a repetition strategy, and that high trait anxiety impaired performance in all conditions relative to low trait anxiety. Comparisons of the values shown along the bottom row of Table 1 suggest that the performances of high and low trait anxious subjects were numerically comparable under the imagery strategy. By contrast, the relative performance of high trait anxious subjects was obviously impaired under repetition strategy. An analysis of variance showed that main effects of Similarity $[F(1,120)=6.26]$, Instructional Set $[F(1,120)=$ 22.16], and Trait Anxiety $[\mathrm{F}(1,120)=4.24]$ were all reliable (at least $\mathrm{p}<.05$ ). However, no interaction effects were significant.

Because of the large degree of difference in variance associated with the similarity variable, the low-similarity and high-similarity data were analyzed separately. Analysis of the low-similarity conditions indicated that main effects of Trait Anxiety $[\mathrm{F}(1,60)=5.46]$ and of Instructional Set $[F(1,60)=15.21]$ were found to be significant at $p<.05$. The Anxiety by Instructional Set interaction $[\mathrm{F}(1,60)=3.78]$ approached the criterion for significance, $p<.056$, suggesting that the imagery instructions attenuated errors generated by high anxiety. Inspection of the top row of Table 1 shows that the

Table 1

Mean Total Errors (Standard Deviation) per Subject as a Function of Instructional Set, Similarity, and Trait Anxiety

\begin{tabular}{|c|c|c|c|c|}
\hline & \multicolumn{2}{|c|}{ Imagery Instructions } & \multicolumn{2}{|c|}{ Repetition Instructions } \\
\hline & $\begin{array}{c}\text { Low } \\
\text { Anxious }\end{array}$ & $\begin{array}{c}\text { High } \\
\text { Anxious }\end{array}$ & $\begin{array}{c}\text { Low } \\
\text { Anxious }\end{array}$ & $\begin{array}{c}\text { High } \\
\text { Anxious }\end{array}$ \\
\hline High Similarity & $\begin{array}{c}17.75 \\
(16.34)\end{array}$ & $\begin{array}{c}22.88 \\
(20.30)\end{array}$ & $\begin{array}{c}37.81 \\
(17.54)\end{array}$ & $\begin{array}{r}49.50 \\
(43.98)\end{array}$ \\
\hline Low Similarity & $\begin{array}{c}16.63 \\
(9.69)\end{array}$ & $\begin{array}{c}17.75 \\
(10.54)\end{array}$ & $\begin{array}{c}22.25 \\
(8.20)\end{array}$ & $\begin{array}{c}34.56 \\
(16.03)\end{array}$ \\
\hline Mean & 17.19 & 20.32 & 30.03 & 42.03 \\
\hline
\end{tabular}


Table 2

Mean Total Errors (Standard Deviation) Per Subject as a Function of Instructional Set, Similarity, Trait Anxiety, and State Anxiety

\begin{tabular}{|c|c|c|c|c|c|}
\hline & \multicolumn{2}{|c|}{ Imagery Instructions } & \multicolumn{2}{|c|}{ Repetition Instructions } & \multirow[b]{2}{*}{ Mean } \\
\hline & $\begin{array}{c}\text { Low } \\
\text { Trait } \\
\text { Anxious }\end{array}$ & $\begin{array}{c}\text { High } \\
\text { Trait } \\
\text { Anxious }\end{array}$ & $\begin{array}{c}\text { Low } \\
\text { Trait } \\
\text { Anxicus }\end{array}$ & $\begin{array}{c}\text { High } \\
\text { Trait } \\
\text { Anxious }\end{array}$ & \\
\hline \multicolumn{6}{|l|}{ Low State Anxious } \\
\hline High Similarity & $\begin{array}{c}7.63 \\
(3.66)\end{array}$ & $\begin{array}{c}16.50 \\
(12.49)\end{array}$ & $\begin{array}{c}33.75 \\
(20.13)\end{array}$ & $\begin{array}{c}37.88 \\
(27.09)\end{array}$ & 23.94 \\
\hline Low Similarity & $\begin{array}{c}19.25 \\
(9.44)\end{array}$ & $\begin{array}{c}15.50 \\
(7.15)\end{array}$ & $\begin{array}{c}21.88 \\
(10.44)\end{array}$ & $\begin{array}{c}30.75 \\
(\quad 6.56)\end{array}$ & 21.84 \\
\hline \multicolumn{6}{|c|}{ High State Anxious } \\
\hline High Similarity & $\begin{array}{c}27.88 \\
(18.02)\end{array}$ & $\begin{array}{c}29.25 \\
(25.18)\end{array}$ & $\begin{array}{c}41.88 \\
(14.70)\end{array}$ & $\begin{array}{c}61.13 \\
(55.70)\end{array}$ & 40.00 \\
\hline Low Similiarity & $\begin{array}{c}14.00 \\
(9.83) \\
\end{array}$ & $\begin{array}{r}20.00 \\
(13.24) \\
\end{array}$ & $\begin{array}{c}22.63 \\
(\quad 5.90) \\
\end{array}$ & $\begin{array}{c}38.38 \\
(21.78) \\
\end{array}$ & 23.75 \\
\hline
\end{tabular}

same pattern of errors existed in the high-similarity data. However, when an analysis of variance was performed, only a main effect of Instructional Set $[\mathrm{F}(1,60)=11.94]$ was significant at $\mathrm{p}<.05$.

Following the analysis of the effect of trait anxiety, the data were reanalyzed, with state anxiety measures taken into account. Within each condition a median split was made based on the state anxiety scores, so that low and high state scores refer to a classification within the trait scores. This breakdown created four anxiety groups: low trait anxious subjects with low state anxiety, low trait anxious subjects with high state anxiety, etc. This type of breakdown was first made using the state anxiety scores taken before the experiment was begun, State-1 measures. The results were identical to those obtained from the initial analysis. The state anxiety measures reflecting anxiety during the experiment were similarly analyzed, State-2. Table 2 provides the mean total errors and standard deviations per subject as a function of each condition. In addition to reconfirming the effects of the other variables, this analysis indicated that the state anxiety of the individual also appeared important. As shown in the last column of Table 2, the performance of high state anxious subjects was more affected by the similarity variable than was the performance of low anxious subjects. Main effects of Similarity $[F(1,112)=6.49]$, Instructional Set $[F(1,112)=22.96]$, Trait Anxiety $[F(1,112)=$ 4.39], and State Anxiety $[F(1,112)=3.87]$ were all significant at $\mathrm{p}<.05$. The Similarity by State Anxiety interaction $[F(1,112)=3.87]$ approaches the criterion for significance, $\mathrm{p}<.053$. No other interactions emerged.

\section{DISCUSSION}

High levels of anxiety reliably impaired performance on this task and, as noted in the introduction, this finding is consistent with the existing literature. These data provide weak evidence for the hypothesized relationships between anxiety and cognitive processing. High state anxious subjects are more impaired by high similarity than are low-anxious subjects. In addition, an effective learning strategy like interaction imagery attenuates the differences in performance between high and low trait anxious subjects, differences that are apparent when a poor strategy like repetition is used. The efficiency of imagery instructions in reducing the recall deficit of high-anxious subjects should be given special notice because of its importance in applied settings. Anxious subjects, when given an efficient learning strategy, can perform at levels comparable to low-anxious subjects, even in a relatively complicated task.

These findings are consistent with the results obtained by Mueller and Schwartz. The major theoretical component of their approach is based on levels-of-processing models, which principally assume that words possess many attributes and that these attributes are coded at different levels of memory. The work of Nelson et al. (1974) suggests that graphic and phonetic information is coded rapidly, while other attributes, semantic and imaginal, for example, require more processing time and represent a different level of processing. Mueller and Schwartz each suggest that high-anxious subjects, for as yet unspecified reasons: (1) tend to focus on graphic-phonetic word attributes, and (2) are impaired in the processing of semantic or imaginal word attributes. These data provide weak support for their observations.

There is one methodological issue raised by the experiment. The present study suggests that trait anxiety measures may be sufficient for the selection of groups and, as indicated by the interaction of instructional set and trait anxiety, these measures may provide some important information about individual differences in cognition. Nevertheless, a significant amount of noise may be generated when low trait anxious subjects become highly anxious in the experimental context or when high trait anxious subjects fail to be so aroused. For this reason, the anxiety present during the task itself should be measured as a standard procedure.

\section{REFERENCE NOTE}

1. Mueller. J. H. Subject differences in breadth of encoding in memory. Paper presented at annual meeting of the American Psychological Association, New Orleans, September 2, 1974.

\section{REFERENCES}

BowER, G. H. A multicomponent theory of the memory trace. In K. W. Spence \& J. T. Spence (Eds.). The psychology of learning and motivation (Vol. 1). New York: Academic Press, 1967.

Craik, F. M., \& Lockhart, R. S. Levels of processing: A framework for memory research. Journal of Verbal Learning and Verbal Behavior, 1972, 11, 671-684. 
Gouler, L. R. Anxiety (drive) and verbal learning: Implications for research and some methodological considerations. Psychological Bulletin, 1968, 69, 235-247.

Nelson, D. L., Wheeler, J. W., Borden, R. C., \& Brooks, D. H. Levels of processing and cuing: Sensory vs. meaning features. Journal of Experimental Psychology, 1974, 103, 971-977.

Nelson, D. L., Wheeler, J. W., \& Brooks, D. H. Meaning and the elimination of sensory interference. Journal of Experimental Psychology, 1976, 2, 95-102.

Paivio, A., Yuille, J. C., \& Madigan, S. Concreteness, imagery and meaningfulness values for 925 nouns. Journal of Experimental Psychology Monograph Supplement, 1968, 76, Pt. 2.

Posner, M. I., \& Warren, R. E. Traces, concepts and conscious constructions. In A. W. Melton \& E. Martin (Eds.),
Coding processes in human memory. Washington, D.C: Winston, 1972.

SChWARTz, S. Individual differences in cognition: Some relationships between personality and memory. Journal of Research in Personality, 1975, 9. 217-225.

SPIElberger, C. D. (Ed.), Anxiety and behavior, New York: Academic Press, 1966.

SPielberger, C. D., Gorsuch, P., \& Lushene, R. State trait anxiety inventory: Preliminary test manual. Palo Alto, Calif: Consulting Psychologist Press, 1969.

Wickens, D. D. Encoding categories of words: An impirical approach to meaning. Psychological Review, 1970, 77, 1-15.

(Received for publication June 21, 1976.) 